\title{
Features of Child-Parent Relations in Dysfunctional Families During the Introduction of Restrictive Measures Due to The Coronavirus Pandemic
}

\author{
Sayakin V.Y. ${ }^{1,}$ Matveeva N. E. ${ }^{1}$ Zhukovskaya E. V. ${ }^{1,2}$ \\ ${ }^{1}$ Moscow Social Pedagogical Institute, Moscow, Russia \\ ${ }^{2}$ State budgetary institution of the city of Moscow Center for social assistance to families and children "Family», \\ Moscow, Russia \\ *Corresponding author. Email: vsayakin@mail.ru
}

\begin{abstract}
The article reveals the problems of child-parent relations during the introduction of restrictive measures due to the coronavirus pandemic. The analysis of intra-family situations of child-parent relations in dysfunctional families assigned to support the children's services and the social assistance Center is carried out. The dynamics of changes in dysfunctional families during the restrictive measures are evaluated.
\end{abstract}

Keywords: child-parent relations, dysfunctional family, psychological problems, pandemic, COVID-19

\section{INTRODUCTION}

The study of parent-child relationships remains one of the most relevant areas of research in psychological science. Domestic and foreign authors noted the importance of the influence on the mental development of the personality of various social institutions, primarily the family. The connection between the mental development of a child and parent-child relationships in the family was noted by many authors: L.S. Vygotsky, M.I. Lisina, L.I. Bozovic, A. Ya. Varga, E.G. Eidemiller, A.S. Spivakovskaya, E. Erickson, F. Dolto, and others.

Within the framework of Vygotsky's cultural and historical concept, the development of a child is determined by his interaction with an adult, and the process of communication between a child from early to school age and adult life has been well studied by M.I. Lisina [7]. In her opinion, the child has two basic innate needs physiological and new impressions. On their basis, the need for communication develops, the main role in this process is played by the initiative appeals of an adult $[5,7]$. N.V. Basova defines child-parental relations as a set of parental, emotional attitude to the child, the child's perception of the parent, and ways of behaving with him, as well as the child's response to the parents [2, p. 86]

Based on this, it can be argued that parent-child relationships are a system of relationships that develop inside the family, which includes the child's emotional attitude towards parents and parents towards him, the child's perception by the parents, and the child's perception of the parents, as well as the ways of behavior and communication styles installed between them. The concept of child-parental relationship is much broader than just a relationship, which in the psychological literature is understood as the subjective side of the surrounding reality's reflection, the result of human interaction with the environment [5]. The relationship in the parental family, the relation to the child from the parents can form a harmoniously developed personality with a positive outlook on the world and oneself. A person who knows how to take responsibility for his actions and ready for self-determination. The same factors, but with different psychological content, can lead to defective personality development, low self-esteem, lack of confidence in others, deficiency in communication with peers, which leads to low potential for self-realization. The phenomenology of research devoted to the problem of parent-child relations is quite extensive both in domestic and foreign psychology. Much attention is paid to the analysis of the social environment's influence on the formation of the personality, the analysis of the upbringing's styles, as well as the relationship in the parent-child dyad in situations of conflict and crisis.

The COVID-19 pandemic and the subsequent situation of forced self-isolation represent completely new atypical circumstances for perception and understanding that need to be realized, and constructive ways of existence must be built. In modern conditions, for psychological science, as well as for other sections of humanitarian knowledge, it is important to determine the attitude to the new social situation and understand the specifics of the ongoing changes. We can state that self-isolation, quarantine, and pandemic are forced measures that significantly changed the usual way of life. On the one hand, a change in the usual way of life can be viewed as a resource for the development of professional and cultural potential, the possibility of more productive communication and interaction with family and friends. 
At the same time, many researchers $[4,6,12]$ note that the spread of coronavirus infection by the nature of the threat and the psychological consequences that it causes can be defined as a psycho-traumatic situation. One of the possible sources of stressful experiences in the current situation is abrupt changes in the usual way of life (forced self-isolation, being in a confined space, changes in the work regime, the schedule of classes, a decrease in the number of direct social contacts, a sense of routine in daily life, etc.) [4 ]. E. V. Fedosenko in his analytical review of the quarantine psychological consequences studies points out acute stress disorder, an increase in anxiety, fear, apathy, and stupor both at the individual and interpersonal levels [4]. In turns of systemic family therapy, the increase in the number of physical and emotional abuse is understood as a response of a dysfunctional family system of relationships to the impact of changed living conditions. They turn out to be a trigger for the intensification of communication's aggressive forms in the family, which existed even before the spread of coronavirus. This process can be described as follows: after the increase in the closeness of the family's external borders, the fusion between its members within it increases; the factor of physical isolation causes a breakdown (or transition to online) external contacts with relatives and friends and can increase reactivity in relations between family members, deplete their psychological resources, weaken protective mechanisms and lead to an increase in conflicts, and in some cases - violence.

We see that the indicated dynamics of interpersonal relations in the family are legitimate for both the spousal and child-parental subsystems $[4,12]$. Due to the urgency of the problem, it seems interesting to us to study the features of parent-child relationships in disadvantaged families during the introduction of restrictive measures due to the coronavirus pandemic.

\section{RESEARCH METHODOLOGY}

The study was based on the material obtained in the course of work on the provision of psychological assistance to parents and children whose families have troubles with varying degrees of severity. When working with families, various documents were studied: protocols drawn up by police officers, acts drawn up by the Commission on minors' affairs and representatives of guardianship authorities, and in some cases, materials received from the judicial authorities. During the consultations, the authors used conversation and observation as the main methods, applied projective psychodiagnostic techniques. For an indepth study of intra-family situations, family visits were carried out to study the dynamics of parent-child relations in those families that were assigned to support the guardianship authorities and the Center for Social Assistance.

\section{RESULTS OF THE STUDY}

Below we present five cases taken from the real practical work of a psychologist in Russia during the period of restrictive measures due to the spread of coronavirus infection. All names below have been changed to maintain confidentiality.

\section{Case 1. Maria, 16 years old, and her mother Olga (53 years old).}

Maria is the youngest child in the family; she lives with her mother, older brother (23 years old), and older sister (30 years old) in the same apartment. The father left the family more than 5 years ago and currently does not support communication with children.

In the summer of 2020, Maria went outside with her classmates in the park near the house, where they drank alcohol. A passing police patrol, seeing a group of children drinking alcoholic beverages, detained and took everyone to the police station, where a protocol was drawn up.

During the first visit to the family, the study of the intrafamily situation was carried out and the risks of staying with family for a girl were assessed.

The girl lives in the same room as her older brother. The bedroom is divided in half by a bookcase. During the study of the peculiarities of living together, it was revealed that the older brother brings women, leaves them for the night, and also makes love to them. Based on the external signs of Mary's mother (puffy face, untidy clothes, inhibited speech), it can be concluded that she is abusing psychoactive substances.

Maria's older brother and sister practically do not communicate with Maria. In general, family relations can be characterized as disharmonious, due to the lack of support from members, especially from the mother, to whom the girl is very attached.

In the situation of introducing restrictive measures, despite the long stay of everyone together, communication between family members occurs fragmentarily and mainly on everyday topics.

Maria, not receiving support from her mother, feeling hopeless on her birthday, not receiving congratulations from family members, feeling lonely, and that no one needed her. She went out into the street in the company of classmates with whom she decided to try alcohol.

In this situation, the mother does not fully understand the risks associated with the incident, underestimating the possible consequences, has insufficient knowledge about the individual and age characteristics of her daughter. It is interesting to note that the mother talked a lot about what a friendly family they have.

Maria is put under control in the guardianship authority and the Center for Social Assistance until the age of majority, the parental competence of the mother is in doubt, the question of a temporary restriction of parental rights has been raised. Both the daughter and the mother should work with a psychologist. But according to 
preliminary estimates, if the mother is not motivated, it is unlikely that she will visit a psychologist. Also, every 3 months the situation in the family will be monitored by going out to the family and observing the dynamics of the situation's development.

\section{Case 2. Konstantin, 17 years old, Dmitry, 15 years old, Andrey, 8 years old, Klavdia, 9 years old and a mother of four children Nina, 40 years old.}

Children were born from three different fathers. All four go to a special school. The mother has been drinking alcohol for more than 10 years.

During the restrictive measures, the mother began to drink alcohol more and more often, the breaks between drinking became less and less.

The eldest son, tired of his mother's constant drunkenness, wrote a statement to the guardianship authorities with a request to be placed in a social center with accommodation so as not to see his mother.

As a result of the examination, it turned out that, during the quarantine, the relations between middle son Dmitry and his mother deteriorated so much that the guy stopped talking and hearing his mother. This was followed by Dmitry's withdrawal into virtual reality and minimizing social contacts not only within the family but also with peers.

The younger children, Andrei and Klavdia, love their mother very much, are quite attached to her, but the mother's frequent use of alcohol, unsanitary conditions in the apartment led to the fact that the guardianship authorities are considering the issue of depriving the mother of parental rights for all of Nina's children with the subsequent definition of children into children houses. It should be noted that as a result of the situation's study, the mother loses contact with children entering adolescence, and this is most clearly manifested in her relationship with Konstantin and Dmitry. A similar situation may likely develop in a few years with Andrei and Klavdia. Of all the children, the mother's attention is mainly focused on the youngest child Andrei, but whether this will be enough motivation for changing the lifestyle and treating the mother for alcoholism is a big question.

\section{Case 3. Ekaterina, 17 years old, mother, 51 years old, father, 55 years old.}

Shortly before the restrictive measures were introduced, the father hit his daughter in the head because his daughter, being in a state of emotional excitement after a quarrel with her father, defiantly pushed the LCD TV to the floor, as a result of which it crashed. The daughter called the police, who recorded the incident. The inflicted beatings were recorded in a medical facility by the established procedure, after which the girl was observed by a neurologist for a month.
As a result of studying the characteristics of intrafamily relations, it was found that the girl does not hide her hostile attitude towards her father, she calls her mother "aunt" or by her first name and patronymic. The girl eats separately from her parents, demonstrates autonomy, is uncritical to her behavior, emotionally labile. Parents do not know how to behave with their daughter.

The girl and her parents were recommended to be monitored by psychologists to establish intra-family relations. Each of the family members refused, saying that they would figure out the situation themselves.

During the introduction of restrictive measures in spring 2020, the girl has made her first attempt at suicide in the presence of a young man. This happened because he did not meet with her at the weekend. The suicide attempt was assessed as demonstrative while the girl was in the hospital, under the supervision of a psychiatrist, during a conversation with whom she admitted that she was not going to die, but only wanted to take revenge on the young man. After this situation, the young man made an independent decision to break off relations with Ekaterina. On the fact of the incident, a conversation took place with Ekaterina and her parents. Doctors recommended placing the girl in a children's psychiatric hospital, but the family refused.

About a month later, at the height of the quarantine, Ekaterina was broadcasting online on one of the social networks, during which she drank more than 10 pills, purchased in advance at the pharmacy. During the online broadcast, the parents were in the next room, watching TV and were unaware of anything. The girl's friends, watching a suicidal attempt online, called an ambulance to the address where Ekaterina lives. The parents found out about what was happening only at the moment of the doctors' arrival. After committing the second suicide attempt, the family again refused the offer of psychological assistance, explaining their refusal by the fact that they were "dragged" to find out the reasons for what was happening. Since both stories were publicized, at the request of the girl, her parents transferred her to another school. The mother claims that the situation has stabilized, but the family will not be removed from control until the girl reaches the age of 18 .

\section{Case 4. Spouses N. (40 and 41 years old), Alina, 16 years old, Denis, 15 years old, Alexander, 7 years old.}

Spouses N., who have three children, decided to divorce in the second half of 2019. In autumn of 2019, the couple began to "share" their three children. The main question is with whom of the parents the children will live. Problems in parent-child relationships began at the same time. The father insulted and beat his son Denis when he refused to move in with him. Alina moved to one of her father's apartments without explaining anything to her mother; besides she stopped all communication with her. Father promised Alina a good life without financial problems. 
Denis, after the incident with his father, stopped attending school, abandoning the sections and extra-curriculum that he had previously attended, and became interested in computer games. The psychological work carried out with Denis allowed him to return to school after a while.

During the introduction of restrictive measures, the father moved Alina and Alexander to his one-room apartment, where the children's grandmother also moved.

Father and grandmother, practically, did not leave the apartment being afraid of contracting the coronavirus; they ate expired food. Grandmother and father drank alcoholic beverages in the presence of children and shared one sleeping place in the kitchen.

Father and grandmother verbally humiliated Alina, did not allow her to attend online classes at school, ridiculed her hobby for English.

One day, suspecting Alina of stealing alcohol, her grandmother began to beat her. The father helped the grandmother to commit violent acts with the use of suffocation techniques against the granddaughter. On the same day, the girl, being in a state of passion, took a suicidal ride out of the window of the 5th floor, but her father was able to hold her back by force. This situation took place in front of 7-year-old Alexander.

Alina's father called an ambulance. To the doctors who arrived on call, the father said that his daughter was a psychopath. On the same day, a mother arrived at the location of the children. She received an SMS the day before from her daughter calling for help. The mother took both children to her place. The beatings were confirmed in a medical facility, her mother asked for psychological help for the children.

1.5 months after the incident, the father kidnapped the youngest son Alexander and took him to another place to live together. After 2 days, the mother, after tracking down the child, took him back.

The situation at the end of the restrictive measures was such that the marriage of N.'s spouses was dissolved, and the place of three children's residence with their mother was determined. The middle child Denis went to school and attended it, but when the ex-husband filed an appeal against the court decision, Denis closed in on himself again, stopped responding to his mother's requests, and stopped attending school. To stabilize the psychological state of the children, the mother asked for help one more time.

Having considered four cases that determine some pattern in the observed picture during the period of the restrictive measures, it should be noted that in the same period, but much less often, other cases were observed, one of which will be given below.

Case 5. Marina, 17 years old, grandmother (guardian), 67 years old.

Since 2009, Marina has been raised by her grandmother. Marina's dad died in 2009, her mother was diagnosed with schizophrenia in 2011 and, after a while, she was deprived of parental rights. The mother became separate from her daughter.

The girl periodically began to have misunderstandings, conflicts with her grandmother. Anastasia Ivanovna, as an elderly person, sometimes did not understand and did not accept the age and psychological characteristics of her granddaughter, trying to insist on her way of solving important issues.

The girl often visited her mother, bought her groceries, and helped with cleaning the house. The sudden death of her mother (39 years old) in February 2020 from pneumonia was a real shock for Marina and Anastasia Ivanovna. Marina felt an incredible sense of guilt - her mother died alone and, according to the girl, if she was next to her mother, she could be saved.

The difficult work of a psychologist with Anastasia Ivanovna, connected with overcoming rigidity, and several consultations with Marina gave a definite result, expressed in the fact that the tragedy that happened brought Marina and Anastasia Ivanovna together. Together, going through a difficult period, they began to better understand each other, help, and support. In individual communication with Marina, the psychologist touched upon the topic of living the loss and searching for resources to gradually improve the psychological state of the girl. In the summer, Marina successfully entered the institute. Today Marina receives support from her grandmother, friends, and her boyfriend.

\section{THE DISCUSSION OF THE RESULTS}

Any research examining the impact of the restrictive measures' introduction due to the spread of coronavirus infection on the family is extremely relevant. Unfortunately, there are practically no publications on this topic yet. It will be possible to carry out a thorough comparison of our results and give a psychological interpretation of the differences in the results obtained by different authors, only if a sufficient number of scientific articles appear soon.

The results presented in this article show that during the period of restrictive measures' due to the spread of coronavirus infection, members of disadvantaged families stay most of the time in the confined space of the house. These processes represent a certain danger because children and their parents lack the skills of successful communication; children and parents often do not hear each other, do not pay due attention, and do not want to give in to each other.

This is because unhappiness in families, unfortunately, has its own history. Disorder and illness do not occur overnight, but gradually develop and deepen. In such a situation, it is naive enough to expect that the limited space at home will force parents and children from disadvantaged families to get closer and look for ways to interact. The four cases cited above tell us exactly that.

Of course, we do not undertake to assert that the situation in such conditions always deteriorates, and relations between children and parents are aggravated.

The fifth case shows that another result is possible, which can be considered positive, when the parent (in this case, the guardian, grandmother) and the child, finding themselves in a difficult life situation, became closer after 
the child's mother passed away. Despite they experienced serious difficulties in interaction together before. This inspires hope that no matter how difficult the situation may be, its subsequent result may be different.

In this regard, it can be stated that the task of a psychologist is not an easy one; he should not provide individual assistance but help the child-parent subsystem as a whole. Each of the parties must understand the importance of their own participation and activity in this situation to solve it. If somebody refuses the offered psychological help, no matter on the side of the child or even the parents, the result is extremely predictable.

\section{CONCLUSION}

In conclusion, it should be noted that the presented results shed light only on some aspects of the development of the intrafamily situation in disadvantaged families. The results we presented show that if we evaluate statistically general trends in the context of the restrictive measures' introduction due to the spread of coronavirus infection, the probability of positive dynamics can be estimated at $20 \%$ (or $80 \%$ of negative dynamics) of the cases' total number with which psychologists work.

The question arises as to how one can assess $20 \%$ of cases with positive dynamics. Is it a lot or a little? Objectively judging, any psychological work cannot be one hundred percent effective. You should not undervalue the work of a psychologist, arguing that it would be good to help all dysfunctional families. You cannot help everyone, since help cannot be imposed.

We should not forget that we are now considering not ordinary families, but a dysfunctional one. Therefore, the results of work with different categories of families must, of course, be assessed separately.

It should be borne in mind that during the action of restrictive measures, the work of a psychologist is difficult since the range of possible actions is limited. At the same time, it should be mentioned that all the cases described above continue to be monitored, and this means that the work on the provision of psychological assistance is not finished.

\section{REFERENCES}

[1] A.A. Aladin, Intrafamily relations in families of adolescents with behavioral disorders: Abstract of thesis .... Cand. psychol. Sciences: 19.00.07, Nat. Institute of Education, Minsk, 1996, 18p.

[2] N.V. Basova, Pedagogy and practical psychology: a textbook, Rostov n / A, Phoenix, 2010, $416 \mathrm{p}$.

[3] M. Bowen, About the processes of differentiation of one's "I" in the parental family, Murray Bowen's theory of family systems: basic concepts and clinical practice, M. Kogito-Center, 2005, pp.81-106.

[4] Yu.V. Bykhovets, L.B. Kogan-Lerner, The COVID-19 pandemic as a multifactorial traumatic situation Institute of Psychology of the Russian Academy of Sciences, Social and Economic Psychology. 2020. Volume 5, No. 2018.

[5] T.A. Velikotskaya, Features of parent-child relationships in the family during the period of crisis development: methods of psychological correction, Scientific Almanac, 2020, No. 7-1 (69), pp. 176-179.

[6] S.N. Enikolopov, O. M. Boyko, T. I. Medvedeva, O. Yu. Vorontsova, O. Yu. Kazmina, Dynamics of Psychological Factors at the Initial Stage of the COVID-19 Pandemic, Psychological Newspaper, 28.04 .

[7] E.M. Izhvanova, Problems of parent-child relations, Moscow: INFRA-M, 2015.

[8] E.A. Sorokoumova, E.I. Cherdymova, E.B. Puchkova, L.V. Temnova, Students during the COVID 19 Pandemic: Understanding the Situation of SelfIsolation, Scientific Review, Series 1: Economics and Law, 2020, No. 3, pp. 196-205.

[9] E.I. Cherdymova, A.R. Masalimova, E.R. Khairullina, D.G. Vasbieva, N.P. Ismailova, R.A. Kurbanov, A.A. Tyazhelnikov, Peculiarities of math students adaptation to temporary forced isolation or quarantine Eurasia Journal of Mathematics, Science and Technology Education, 2020, T. 16, № 11, 1892.

[10] Children in family cotexts: perspectives on treatment, ed.L. Combrinek Graham. 2nd ed., New York, Guilford Press, 2006, 524 p.

[11] Evaluating and treating families: the Mc Master approach, Cristine E. Ryan [et al.], New York, Routledge, 2005, 335 p.

[12] H. Prime, M. Wade, D.T. Browne, Risk and resilience in family well - being during the COVID -19 pandemic, American Psychologist, 2020, DOI: http://dx.doi.org/10.1037/amp0000660 